\title{
FUZZY LOGIC IN ENGINEERING EDUCATION AND EvaluATION OF GRADUATE ATTRIBUTES
}

\author{
Mory Ghomshei \\ Department of Mining and Mineral Resources Engineering, British Columbia Institute of Technology \\ mmohieddinghomshei@bcit.ca
}

\begin{abstract}
Fuzzy logic, which was invented in 1960's, in response to emerging needs to deal with complex techno-social concepts, is becoming more and more relevant to today's problems. Nowadays, fuzzy logic should not only become a part of the engineering curriculum but also a part of the engineering education standards. For example a fuzzy approach can be used in evaluating graduate attributes (GAs). Most graduate attributes are fuzzy and need to be evaluated using a fuzzy logic methodology.

The present paper is an attempt to introduce fuzzy tools (such as fuzzy sets and fuzzy linguistic value systems) to provide a metric for defining and evaluating graduate attributes. Proper definition and scaling of fuzzy attributes can provide a common language, through which educators, industry, and regulators can communicate and collaborate more effectively in the process of assigning jobs to engineers with attributes which best fit the task. Also, by using a fuzzy method, the uncertainty of attributes is neither magnified nor dampened in the analytical process (contrary to most conventional approaches).

A properly defined fuzzy metric for GAs can provide flexibility in the implementation of the system, while reducing the overall errors in evaluation. Graduate attributes are proposed to be divided into three major classes or spaces (i.e. knowledge, social and ethical), each consisting of a number of fuzzy attributes and sub-attributes, which can be summed up with appropriate weighting factors. A neural network engine can be used to find the optimal weighting factors.
\end{abstract}

Keywords: Engineering education, engineering standards, engineering graduate attributes, fuzzy logic in education, fuzzy metric, graduate attribute evolution. Classification of graduate attributes.

\section{INTRODUCTION}

Engineering is directly related to the dynamic needs of societies. Engineering education should therefore adjust itself in response to the rapid and pivotal changes that our societies are actually going through. The post-modern socio-technical revolution (with enormous advances in access to information, processing of information and AI applications) commands a paradigm shift in engineering education.

The rational for a paradigm shift was seriously felt about two decades ago. Yet the engineering community is still trying to find pathways from a modern to a postmodern era. Such a transition, which would happen sooner or later, should take into consideration a redefinition of objectives of engineering, firstly from "economic development" to "sustainable development" and secondly from "conventional technologies" to "creative and innovative applications". The desired attributes of engineering graduates will therefore be rapidly changing in response to the demands of our "brave new world".

In facing a paradigm shift in engineering, the industry has been more avant-garde compared to the education community. Boeing, in early 1990's [1], published a list of desired attributes of an engineer as follows:

- a solid understanding of:

$\circ$ engineering science fundamentals, $\circ$ design and manufacturing processes,

0 the context in which engineering is practiced,

$\circ$ a multi-disciplinary, systems perspective;

- good communication skills;

- high ethical standards,

- an ability to think both critically and creatively, independently and cooperatively;

- flexibility; 
- the ability and self-confidence to adapt to rapid or major change;

- $\quad$ curiosity and a desire to learn for life; and

- a profound understanding of the importance of teamwork.

To these attributes one can add "vision" and "tolerance". Vision for an engineer can be defined as the ability to think and act above and beyond temporality and locality [2]. As for tolerance, it can be defined as the ability to embrace, new and unfamiliar things (including ideas, cultures and approaches) with an open heart and open mind. Note that while flexibility (as included in the Boeing's list of engineers' attributes) is a feature which mostly concerns the design, tolerance is commonly an acquired character attribute, which can be part of a social group of engineering attributes.

In moving from a conventional engineering education toward a post-modern one, educators should try to define practical metrics for desired attributes. To this end, fuzzy logic can replace the conventional binary logic, considering its inherent tolerance and flexibility.

Application of fuzzy logic in education began in 1990's. Echauz and Vachtsevanos, [3], defined a fuzzy grading system, based on the traditional letter-based systems, in which a fair mark distribution can be achieved through using students' and instructor's performances measures to modify fuzzy grades. Fourali [4] argues that a fuzzy system can provide insight into complex portfolio-based deliberations.

More recent works [5] have explored specific applications of fuzzy logic in engineering evaluation systems, such as project-based works. With progress in outcome-based assessments, fuzzy logic has proved to be a powerful tool, providing reasonable metrics for both input and output data in educational assessments [6]. This paper is a discussion on the ability of fuzzy tools in defining metrics and scales for assessing graduate attributes in engineering.

\section{FUZZY APPROACH}

One of the important tools in fuzzy logic (or fuzzy approach) is fuzzy set, which can be defined [7] as a set containing elements that have varying degrees of membership in the set. In mathematical terms, if an element of universe, say $x$, is a member of a fuzzy set, then the mapping is given by $\mu(x) \in[0,1]$.

The theory of fuzzy sets has been proposed in terms of the membership function operating over the range [0-1] of real numbers, in contrast with classical or crisp sets, where "members would not be members in the set unless their membership is full or complete" $[8,9,10]$.

A fuzzy set can be defined as the distribution of the "Degree of Belief" in a particular quantitative or qualitative concept over the range of its variations [10]. The Degree of Belief (DoB) can provide a metric to assess the degree of uncertainty in the input data, which can be inherently fuzzy.

In transition from a crisp method to a fuzzy approach, one should, in a first step, fuzzyfy the input variables. The fuzzification of the input space can be done using fuzzy linguistic values, consisting of a number of values (e.g. 3 values in one of its simplest forms). The three-value fuzzy linguistic input variables cab be defined for example as "slightly", "moderately" and "substantially". Similarly, the output variables can be graded as "poor", "satisfactory" and "excellent. The second step in fuzzy approach is fuzzy processing or inference engine [6], which should be built in a way that the uncertainty of the data is neither amplified nor suppressed in the process [11]. A third stage can be defuzzification, which can involve converting the fuzzy output of the process to crisp values, using a membership similar to fuzzification. Fuzzy variables can be scaled with the Degree of Belief both in the input and the output data (Fig. 1).

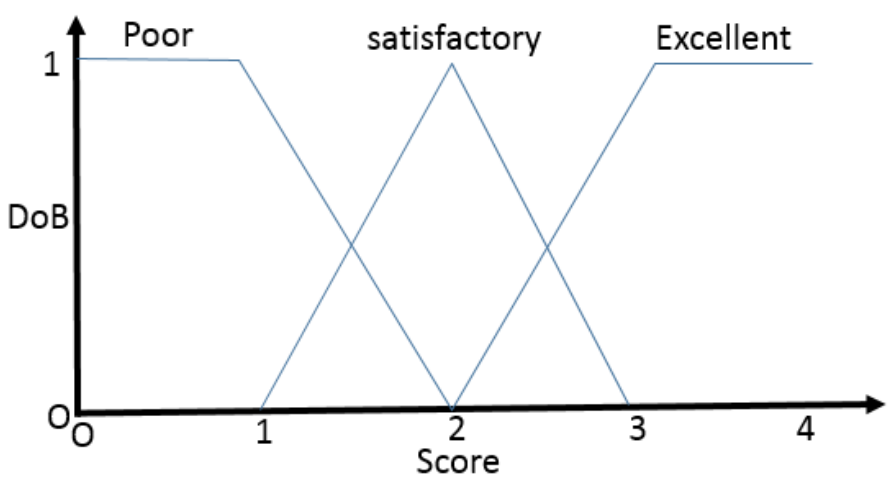

Fig. 1 - Fuzzy representation of educational assessments, tuning a numerical scale (e.g. 1 to 4 ) to the Degree of Belief (Do B). 
In a fuzzy assessment of graduate attributes, each GA can get a value in DoB (Degree of Belief) in the range $[0,1]$ based on the overall outcome of the GA evaluation data. The fuzzy GA evaluation could thus be mapped on a fuzzy linguistic set with three (poor, satisfactory, and excellent) members (Fig. 1). The number of linguistic values can be 2,3 , or higher numbers (e.g. 5) comprising intermediate values between the 3 major values. It should, however, be born in mind that we should avoid forcing quantity into concepts which are qualitative by nature and by functionality. One may try to impose, for example, a scale of 1 to 100 to a qualitative concept (like responsibility) but the numbers could only add to the confusion. It is for this reason that the employers try to fuzzyfy the numeric marks or grades in order to generate a set of more meaningful values (such as poor, satisfactory, and excellent).
Fuzzy rules should be defined to map the complex GA data (as collected by instructors) onto fuzzy linguistic values. These rules make an essential part in the fuzzy modeling, for mapping the data into the input and output spaces.

\section{PROPOSED MODEL}

Each graduate attribute can be defined as a vector and a group of attributes as a tensor. Attributes themselves can be classed in three major groups or spaces namely, "Knowledge", "Social" and "Ethical". Each group can be defined by a series of categories which are directly or indirectly related to that group (tables 1 to 4 ).

Table 1 - graduate attributes related (directly or indirectly) to knowledge. $\mathrm{w}_{\mathrm{i}}$ is the weighting factor in summation

\begin{tabular}{|l|l|l|l|l|l|l|l|}
\hline & Fundamentals & Design & Context & Objectivity & Multidisciplinary & Vison & Sum \\
\hline Knowledge & K1 & K2 & K3 & K4 & K5 & K6 & $\begin{array}{l}\mathrm{K}= \\
\Sigma \mathrm{W}_{\mathrm{i}} \mathrm{K}_{\mathrm{i}}\end{array}$ \\
\hline
\end{tabular}

Table 2 - graduate attributed related (directly or indirectly) to social performance

\begin{tabular}{|l|l|l|l|l|l|}
\hline & Communication & $\begin{array}{l}\text { Group } \\
\text { work }\end{array}$ & $\begin{array}{l}\text { Social } \\
\text { knowledge }\end{array}$ & $\begin{array}{l}\text { Sensitivity and } \\
\text { tolerance }\end{array}$ & Sum \\
\hline Social & $\mathrm{S} 1$ & $\mathrm{~S} 2$ & $\mathrm{~S} 3$ & $\mathrm{~S} 4$ & $\mathrm{~S}=\Sigma \mathrm{w}_{\mathrm{i}} \mathrm{S}_{\mathrm{i}}$ \\
\hline
\end{tabular}

Table 3 - graduate attributes related (directly or indirectly) to ethical behavior

\begin{tabular}{|l|l|l|l|l|l|l|}
\hline & $\begin{array}{l}\text { Honesty, } \\
\text { transparency } \\
\text { and integrity }\end{array}$ & Accountability & $\begin{array}{l}\text { Confidentiality } \\
\text { and loyalty }\end{array}$ & Professionalism & $\begin{array}{l}\text { Law } \\
\text { abiding }\end{array}$ & Sum \\
\hline Ethical & E1 & E2 & E3 & E4 & E5 & $\mathrm{E}=\Sigma \mathrm{w}_{\mathrm{i}} \mathrm{E}_{\mathrm{i}}$ \\
\hline
\end{tabular}

Table 4 - overall graduate attributes - weighted summation of 3 groups of attributes

\begin{tabular}{|l|l|l|l|l|}
\hline & Knowledge & Social & Ethical & Sum \\
\hline Overall engineering attributes & $\mathrm{O} 1$ & $\mathrm{O} 2$ & $\mathrm{O} 3$ & $\mathrm{O}=\Sigma \mathrm{w}_{\mathrm{i}} \mathrm{O}_{\mathrm{i}}$ \\
\hline
\end{tabular}

The overall Engineering quality can therefore be defined by a summation of the three groups of attributes (table 4). In assessing the overall engineering attributes of engineering graduates a weighted summation can be adopted. The weights can be modified or fine-tuned in a Neural Network Engine to optimize the functionality of graduates depending on specific demands of the position. For example for a managerial job, the social and ethical components could be given higher weighting factors, compared to that of the knowledge. It should also be noted that evaluation of individual attributes (such as communication in the social group) can itself be based on a weighted summation of a number of subattributes (such as oral communication, written communication, behavioral communication, etc.).

\subsection{CONCLUSION}

Fuzzy logic can provide practical tools in finding metrics and scales for assessing graduate attributes in engineering. Graduate attributes are proposed to be divided into three major groups of attributes, each consisting of a number of attributes and sub- 
attributes. The summation of attributes and subattributes is proposed to be carried out by giving higher weights to the more desired attributes (depending on the needs of the market).

\section{References}

[1] Boeing. (n.d.). Desired attributes of an engineer. Retrieved February 1, 2009, from website: http://www.boeing.com/educationrelations/attribu tes.html

[2] Mory Ghomshei (2010). Postmodern sustainability. International Journal of Engineering and Interdisciplinary Mathematics. 2010., Volume 1 No. 2. Pp. 103 - 106

[3] J. R. Echauz and G. J. Vachtsevanos, (1995) -Fuzzy grading system,\| IEEE Trans. Educ., vol. 38 , no. 2 , pp. $158-164$,.

[4] Fourali, C. (1997). Using fuzzy logic in educational measurement: The case of portfolio assessment. Journal of evaluation and research in education, 11(3). 129-148.

[5] Molyneaux, T. Setunge, S. Gravina, R. and Xie, M. (2006). An evaluation of the learning of structural engineering concepts during the first two years of a project-based engineering degree, European Journal of Engineering Education, 32 (1), 1-8.
[6] Abraham Varghese, Shajidmon Kolamban, Jagath Prasad Sreedhar, Sankara Nayaki (2017). Outcome based Assessment using Fuzzy Logic. (IJACSA) International Journal of Advanced Computer Science and Applications,

[7] Zadeh, L.A. Fuzzy sets. Inf. Control 1965, 8, 338-353.

[8] J. R. Echauz and G. J. Vachtsevanos, (1995) -Fuzzy grading system,\| IEEE Trans. Educ., vol. 38, no. 2, pp. 158-164,.

[9] G. J. Klirm and B. Yuan, (1995) Fuzzy Sets and Fuzzy Logic: Theory and Applications. Englewood Cliffs, NJ: Prentice-Hall.

[10] Feng and L. D. Xu, (1999) -Decision support for fuzzy comprehensive evaluation of urban development, Fuzzy Sets Syst. , vol. 105, pp. 112.

[11] Mory M. Ghomshei, John A. Meech (2000), Application of fuzzy logic in environmental risk assessment: some thoughts on fuzzy sets. Cybernetics and Systems, An International Journal Volume 31, 2000 - Issue 3. pp. 317-332 